\title{
Building a capable state through proper human resource management
}

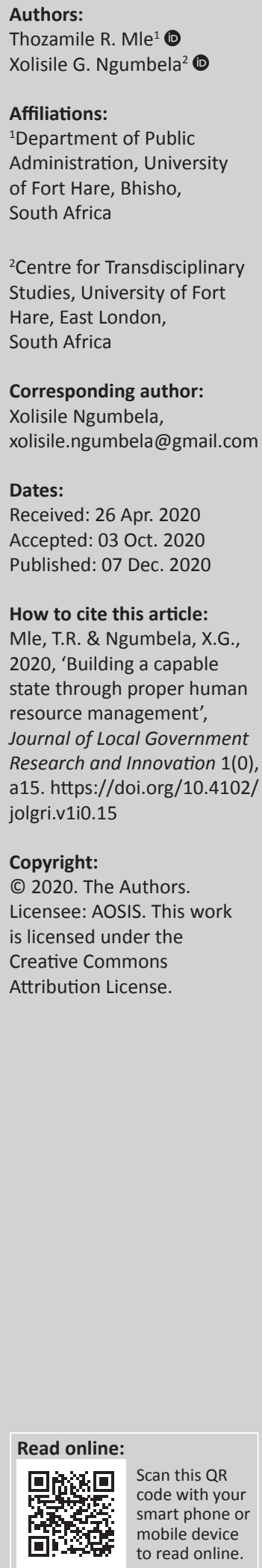

Background: This article examines the possibility of building a capable state within an appropriate ethical framework and the required human capital spectrum available to a government. South Africa currently faces shortcomings in capability and systemic stasis because of weak political management. The existing research has pointed out the state's capacity deficit as a major factor that undermines the social and economic progress of South Africa.

Aim: The aim of this article was to look at government's capability of building a capable, ethical and developmental state which is a crucial facilitator for the successful execution of government's goals of achieving the targets of the 2030 National Development Plan. A developmental state that is going to develop the economy, create jobs and improve the conditions of society standard of living through proper human resource management.

Methods: As the main tool for doing this research, this article relied heavily on secondary qualitative and quantitative data analysis. Secondary analysis is a study technique that uses pre-existing quantitative data or pre-existing qualitative research data to analyse or validate previous studies on new issues.

Results: The findings point that capacity building is crucial. Fixing political control at the core should be the starting point.

Conclusion: There seems to be a complete failure of a build-up towards a capable state in South Africa as the public service shows unevenness with local, provincial and national government capability challenges. A capable state can exist only when an affordable, effective and development-orientated public service can only grow and have a transformative function in order to correct past failures, where government is making drastic changes, enhance and have the requisite effect on society on its bad results.

Keywords: efficiency; effectivity; economically; skills and professionalism; accountability; responsibility efficiency.

\section{Introduction}

The Parliament of the Republic of South Africa (1994) White Paper stated that South Africa inherited a public service whose role in bringing about economic and social justice is critical but the capacity to do so is severely constrained by obsolete and inappropriate human resource management practices. Consequently, transforming the way human resources were managed was the catalyst for the public service's transformation itself. A professional and impartial public service that is representative of all sections of society was essential for an effective government and for achieving the democratic, economic and social goals of South Africa. According to the Public Service and Administration Department, turning the public service into an instrument capable of fulfilling its role in bringing about the new South Africa depends on many things, but mainly on the dedication and effectiveness of its employees, which in turn depend on how those employees are handled. However, the National Development Plan (NDP) notes that capacity inequality is one of the main challenges in building a capable and developmental state. This results in inconsistent performance in local, provincial and national governments. In historically disadvantaged countries, weaknesses in capacity and performance are most serious zones. Yet, it is here that state action is most needed to improve the quality of life for people.

The ethos of this article will be to look at the building of a capable state through the capacity of the public service to properly manage human resources and set out a comprehensive framework for change, in line with those constitutional principles. The transformation agenda should be informed by a quest to improve service delivery and close the gap of inequality as identified in the 
White Paper and advanced through a closer look at policy initiatives that should guide the building of a properly capable state through proper management of human resources. One such key area is the management of local government's human resources and the developmental nature.

\section{Methods}

The study relied heavily on the secondary qualitative and quantitative data analysis as the main method for doing this research. Secondary analysis is 'a research strategy that uses pre-existing quantitative data or pre-existing qualitative research data to investigate new questions or to verify previous studies' (Heaton 2004:16). Consequently, as a source of raw and processed data, various sources of secondary data available on the web pages of national and international organisations, governmental organisations and nongovernmental organisations dealing with food and nutritional security were used. Besides this, electronic and non-electronic, published and unpublished periodicals, books, reports, conference proceedings and newspapers were also used. The researcher was expected to review the literature on the subject in order to better understand the issue of capable state and how it influenced service delivery in South Africa. Most of the literature was collected from publications in the journal relating to the state of being willing. Many of these journals referred to the developmental state survey, which then led the researcher to the website of the Public Service and Administration Department and the numerous publications it has on improved quality of service delivery. Many of these articles referred to other journals, which we found in a web search afterwards. The literature review looked at and critically evaluated the existing works relevant to this subject. The more you study a subject, the better you can understand it, and thus can gain insight into the issue (Leedy 1989). The literature review allowed the researcher to explore how views of the developmental state have changed over the past few years. As this emerges as a central issue in addressing the state's capacity towards the Fourth Industrial Revolution, there is an increasing body of literature on the subject. Three semi-structured interviews with open-ended questions were conducted with developmental state experts to develop a broader perspective on quality service delivery capability systems. Each of these interviews was purposely selected on the basis of the concerned person's area of expertise.

\section{Conceptual and theoretical framework}

The theoretical framework serves as the structure and support for the study justification, the description of the issue, intention, significance and research questions. The theoretical structure provides the literature review, methodology and analysis with a grounding basis or anchor (Grant \& Azadeh 2014:12). Bureaucratic theory in the case of this analysis serves as an adequate tool to build on the analysis. This study is anchored on the theory of bureaucratic management that generally claims to increase the productivity of a company. Max Weber, a German sociologist, concluded that bureaucracy was the most effective and rational model under which private companies and government offices could function. The theories of bureaucracy inspired generations of business executives and politicians well into the 20th century. Although Weber's theory prioritises performance, leaders do not automatically enforce best practice. While efficiency is prioritised by Weber's theory, it is not inherently the best practice for leaders to enforce. Today, Weber was unlike other leaders in the workplace. His management theory, also called bureaucratic theory, stressed on strict rules and a strong distribution of control. He should have scolded today's executives for their leadership style, most of whom are open to fresh ideas and flexible work arrangements. 'Precision, speed, unambiguity, file information, consistency, flexibility, cohesion, strict subordination, friction and material reduction and personal costs are raised to the optimum point in purely bureaucratic administration', Weber wrote.

Weber concluded that the most effective way to set up and run an enterprise was by bureaucracy, and that it was absolutely important for larger organisations to achieve full efficiency with many workers and tasks. Everybody is treated fairly in an ideal workplace, and the job roles are clearly separated by areas of expertise of each staff member. This is supported by a well-defined hierarchical management structure, which provides clear lines of communication and division of labour based on the management layer in which one works. Organisational progress is determined solely by qualifications and achievements, rather than by personal connections. Weber believed that the work environment should be professional and impersonal 'work relationships' are strongly disincentive. Overall, Weber's ideal bureaucracy promotes efficiency, uniformity and clear power distribution.

Public sector innovation can play a critical role as a true enabler and catalyst of better service delivery and socioeconomic development. Consequently, as the South African government is working hard to reform the public sector and the economy, it is imperative that we ensure its role as a key ingredient. According to Dlodlo (2018), and now in the light of the Fourth Industrial Revolution and its imminent implications, the attention of the South African government on the outlook of government is moving to the competent state that offers quality services to all its people. Dlodlo (2018) further argued that government is feeling the enormous pressure to eventually change the approach to revolutionary capable state in line with the influential Fourth Industrial Revolution for countless reasons. The Government of South Africa is part of the global village and is currently facing the same problems related to rapid growth with respect to the state of modern capability. Modern society explores divergent options for addressing current problems using information communication technology (ICT) amongst other items and enhancing service delivery quality. It is in 
this sense that modern governments are under immense pressure to provide rapid and adequate solutions to meet ever-increasing demands for the efficient and successful delivery of socio-economic services whilst keeping pace with technological advances at the same time.

\section{Review findings}

Qobo (2020) defines a capable state as a system of government that functions from narrow ideological interests with relative autonomy. The parts function in a co-ordinated manner to achieve clearly defined objectives. It performs its work efficiently and is effective in delivering critical economic infrastructure and services. Qobo (2020) further argues that a state's core role is to mobilise capital to address its structural challenges and to navigate social and economic transition over the long term. A capable state is ideally positioned to respond to changes and leverage opportunities for growth, with autonomy from political factions. For any state to be deemed capable, Qobo believes that it must be innovative, have human capital as its main development agenda item and recruit competent respected capable managers who are able to take decisions without fear or favour. If Qobo's assessment of the capable state is any factor to go by, then the big factor that threatens the social and economic growth of South Africa is the state's capability deficit. The National Planning Commission recognised this void long ago, first in its 2011 diagnostic report and again when it released its final NDP in 2012. The plan is a blueprint for the country to fix its problems. They place particular emphasis on economic performance, education, healthcare and infrastructure. The South African state currently operates in a fragmented manner and with no shared vision. The reason it is unable to fulfil its social and economic obligations is because of poor policy choices and faulty political management. Part of the issue is the link between the ruling African National Congress (ANC) political machinery and the state's bureaucratic machinery. Added to this challenge is the fact that the ANC rules through a tripartite coalition with the Communist Party of South Africa and the South African Trade Unions Congress. These seek to influence the policies and decisions of government. Without overcoming these tensions, it is impossible to build the state's capabilities sustainably. This requires a solid nerve centre that should be the presidency in essence. President Cyril Ramaphosa as a president of the country has massive political capital, which is guaranteed by the Constitution of the country (Chapter 10: Administration) and so far it seems that he is underusing as a result of nursing the tripartite alliance that influences the ruling party on cadre deployment rather than following the manifesto promises made to the citizens. What the president needs here is to leverage government-wide resources to accomplish a given set of strategic goals and priorities. And he needs to look down on factional and ideological interests surrounding the state and its agencies. He should then use his executive authority to translate his strategic goals into measurable results that make a noticeable difference in the economy and society that will sharply transform society and diminish inequalities from the past of apartheid. The process of signing performance agreements with government ministers currently under way is a step in the right direction. However, the process seems to be, without any whip cracking scheme, this could fall apart as it did under President Ramaphosa's predecessor Jacob Zuma.

The severity of resource and capacity constraints varies across various levels of government. Some of these concern the underlying political appointments. As is clear from the reports of the Auditor General over the years, capacity deficiencies at the local government level are largely because of a lack of technical skills and failures in execution. Furthermore, groups also systematically ignore advice. Once again, Qobo (2020) agrees with Palmer et al. (2017) that there are expertise deficiencies found in almost all core fields, such as project management, recruitment, contract management and financial management. The capacity for implementing mandates and delivering services to communities is also low. What is crystal clear then is that when it comes to creating great institutions, the other half of a competent state's equation always matters to political management. The parlous condition of state-owned companies, such as the power provider Eskom and South African Airways, makes poor political management apparent. It also became evident in some institutions that are responsible for upholding the rule of law that the capable state is becoming a pipe dream because they showed some defects in upholding the responsible to book. This led to the Zondo Commission's tortuously slow investigation into massive injustice caused by the state entities' failure to uphold efficient and effective management practices as discussed by Qobo, which has yet to lead to any prosecutions. Policy decisions in key economic sectors, such as information and communications technology, oil and mining, also have ambiguities. According to the Conversation Newspaper (2020), the quality of officials who preside over the state defines the norms and standards under which the state's bureaucratic apparatus works. As modern Singapore's founding father, Lee Kuan Yew, pointed out, you have to have good people in charge of government to get good governance. A nation may look good in terms of institutions and policies. Yet if they are not supported by capable and responsible leaders, they are destined to be ineffectual and not achieve their full potential. A capable state cannot be established outside an appropriate ethical structure and the required range of human capabilities at the disposal of a government. Currently, as argued by Qobo and Conversation Newspaper (2020), because of poor political management, South Africa is suffering from capacity deficiencies and institutional stasis.

Seemingly, Qobo and Parnell agree that President Ramaphosa, the key lever of state craftsmanship for achieving results in a democratic society, has to act decisively in making things happen. It includes knowledge of his power and authority, expertise in reading the political climate and a strong desire for decisive action. Certainly, the state president as the state's nerve centre must mean acceptable standards and be hard on errant public officials regardless of party 
affiliation. This should begin with executive members who are underperforming and corrupt. At the municipal and provincial levels, the centre needs to use fiscal tools to stop wastage and poor performance in the other two government spheres. Effective government leaders who lead through moments of crisis should immediately grasp the goals and use of power. With astute political strategy and collective decision-making, they will do even more. They should focus on delivering results instead of fixing on long consultation processes as is the case in South Africa. Finally, there are places where government can achieve rapid wins by wellstructured alliances to address capability gaps. It can tap into private sector capital. For example, a number of mining companies could assist with capacity building at local government level. This could help tackle limitations in places where their workers are employed. Such mutual interest may help boost those companies' credibility. However, we should be careful of private sector firms and business leaders who only want to pursue their narrow interests through proximity to political leadership. Partnerships with both the private sector and civil society should be focused on addressing real and clearly identified problems. Building capabilities is essential for higher performance retooling of the economy. Fixing political management at the centre should be the starting point in this regard.

Fitzgerald further believes that tackling issues related to management leadership place an inadequate emphasis on providing stimulating career pathways that could ensure the replication of skills and promote a sense of shared professional intent. Nevertheless, in terms of the path to a capable state, the main issues raised in Chapter 13 of the NDP (2012) are thus presented up front, honestly and openly. Earlier on as noted by the NDP there seems to be a lack of a clear vision, poor managerial ability and a lack of direction is made.

The problem of the political-administrative interface is one of the primary lengthy debates in the theory of public administration. Apparently, Chapter 13 of the NDP tends to take the classic position, as epitomised by the discipline's alleged founder, Woodrow Wilson, that a clear distinction should be drawn between the political and administrative roles. Although there is no mention of the famous (or infamous) term 'deployment', there is a strong comment on situations where public servants are recruited on the basis of political connections rather than skills and expert access to state resources and services is defined by political affiliation rather than by citizenship. What is not mentioned is the growing phenomenon by which recruitment (or promotion) is justified on alleged political grounds, whereas the reality is pure favouritism, or nepotism or even monetary kick-back in some cases. Various steps are being suggested, including the creation of a Head of Public Service. This is an obviously positive idea as this position acts as a mediating force between the political and administrative spheres in some countries and helps to shield qualified civil servants from unilateral decisions by ministers or other politicians. This suggestion, however, does not seem to have gained much traction over the past 5 years and seems to have fallen away entirely. A further suggestion, made from several sources over the years, is to reinforce the position of the Public Service Commission (PSC).

Again this may be a positive idea, but the question must be raised whether the PSC needs to be enhanced, having legislative independence and far-reaching powers enshrined both in the Constitution and in legislation.

An independent and assertive PSC could indeed improve public service performance immeasurably, but this may have to do with making much better appointments rather than fiddling with existing legislation. Some of the reports of the PSC are quite useful and hard-hitting, but are routinely ignored by the major players involved in governance of the state and the PSC has generally found it fit to leave matters there. Another perspective would be that the PSC is potentially quite strong enough as an institution, according to Fitzgerald and Qobo, but the appointments to the PSC were largely made by people unwilling to change or challenge political office holders' wishes or otherwise unsound decisions and practices. In terms of the politicaladministrative interface in South Africa, a notable problem is that at one level legislative and regulatory lip service is paid to the classical doctrine of a merit public service and a distinction between political and administrative functions, whereas in reality it is a completely open secret that most senior appointments are politically driven. Qobo, Parnell and Fitzgerald agree on widespread political intervention in administrative activities allegedly occurring: to put it more clearly than the NDP writers of Chapter 13 do. According to the above-mentioned authors, it is advisable either to change the practice in order to comply with our current constitution, legislation and set criteria and procedures or to change the legislation on doctrine and regulatory procedures in order to align with the actual custom, practice and culture of public service that South Africa has developed post-apartheid. The latter alternative, that is, getting our ideology and laws in line with our modern society, would seem to be a more viable option, not in the sense of merely enshrining bad practice but through recognising and making the nature, scope and modalities of political appointment transparent. This is what happens in a number of countries that practise political appointment quite openly, and through set procedures - but with the potential harm mitigated and controlled by legislative measures. Think of the United States of America, for example, where government appointments are checked by appointees interviewed in the Senate or Congress; or France, where each president selects a brace of advisors called the ministerial cabinet that counteracts the technological influence of the qualified public service; or Germany, where senior public servant are internally rotated and redeployed after each election to ensure that ministers with politically sensitive portfolios have senior civil servant whom they can trust. Because appointment politicisation (some may say over-politicisation of appointments) is so deeply ingrained in South African tradition and practice that 
there might well be a case for developing a new doctrine and co-legislation to make it clear and reduce the risks of seemingly bad and inappropriate appointments. Although not providing any specifics, the same Chapter 13 of the NDP clears the way for this course of action in terms of its suggestion of a 'hybrid solution' which it hopes 'will allow political and administrative objectives to be reconciled'.

\section{The capable state}

During the period of reconstruction and development the seeds of the new South Africa were planted. Good governance has been a focal point of the long abandoned programme of reconstruction and development, which was commonly known as Reconstruction and Development Programme (RDP 1994). Although local government in the late 1990s had dominated national attention and postapartheid spending, the 'transition to good governance' gradually combined local governance legitimacy with constitutional processes. Determined not to replicate the recent past mistakes, policy leaders engaged in intensive dialogue with 'partners, sponsors, civil society groups and the private sector' to establish a developmental local government system through the NDP, an ambitious progress agenda aligned with the Millennium Development Goals of the United Nations.

According to Qobo (2020) and Pempel (1999: 139), developing countries 'define their missions mainly in terms of long-term national economic enhancement' and 'intervene actively and frequently in economic activities with the aim of enhancing the international competitiveness of their domestic economies'. According to this concept of Qobo and Pempel, the imperative to handle structural change domestically, for example, is followed alongside policies to promote the country as an investment destination for foreign capital, to boost the economic growth profile, diversify the production base and generate jobs. In certain cases, the focus put on the notion of capable state by the ruling party, according to Qobo, emphasises a more teleological thrust articulated in a certain state of completeness and generally in relation to the typology of East Asian nations. Beyond rhetoric, in the post1990 South African background, a time marked by growing globalisation and the emergence of 'footloose' capital preferring locations where the state is seen as less interventionist, it is worth investigating what exactly does capable state mean. It is against this context that the ideology of 'capable state' was embraced by the South African political elite as a slogan for social and economic policy, although the content of economic policymaking was more in line with the way of thinking of the Washington Consensus. However, Johnson (1999:53), who is widely acknowledged for coining the idea of 'developmental state', noted that '[t]he source of authority in the state of development is not one of Max Weber's "holy trinity" of conventional, rational-legal and charismatic authority ...'. According to Johnson (1999:53), capable states are distinguished by the presence of the revolutionary power: the power of a people committed to the transformation of social, political, or economic order'. Johnson further suggests that there is little that distinguishes the leaders of a developing state from those that lead the mass movements.

The National Planning Commission noticed the unevenness in state capacity, which leads to mediocrity performance in local, provincial and national governments. There are a number of factors that lead to this state of affairs. Such factors that entail the management of human resources are, inter alia, discussed in the following sections.

\section{Politics-administration dichotomy}

According to the PSC, the mediocrity in performance in the public sector can be attributed to tensions in the politicaladministrative interface (PSC 2007). The result is instability and internal conflicts in senior posts in the public service and reduced confidence in the leadership. All this grossly affects the delivery of services that undermines the morale of public servants and reduces citizens' confidence in the state. Provision of goods and services gets affected by this human resource issue, which requires proper management.

According to Mle, Maclean and Kanyane (2015:6), in the work environment, decisions that fall within the ambit of officials and within that of politicians should be made clear. Both the politician and the administrator should focus on their respective roles to avoid encroaching on the each other's territory. It is critical that there should be the element of trust and agreement on who should do what, where, when and how. It is argued that politics can theoretically be separated from administration, but it is practically impossible in the real world of work. Politicians and administrators are supposed to trust, co-operate and work in harmony and in attempting to manage the interface, matured, talented and committed people must occupy both offices. Thus, in terms of the Municipal Amendment Act 2011 municipal managers are prohibited from holding political office in a political party, which suggests recognition of the need to achieve a clearer demarcation between the administration and the political environments. According to the NDP Vision 2030 (2011:365), there is a need to focus on building a professional public service that serves government but is sufficiently autonomous to be insulated from political patronage. A point is further made in the NDP that standards can be undermined when public servants are not recruited on the basis of skills and expertise.

\section{Skills deficit}

Professor Patrick FitzGerald (2016) of Wits School of Governance argued that there is a deficit in skills and professionalism that affects most elements of the public service. There is not enough focus on providing stimulating career paths that could ensure the reproduction of skills and foster a sense of professional common purpose. There is a lack of a clear vision as to where the next generation of public servants will come from and how specialist 
professional skills will be reproduced. Because of weak managerial capacity and a lack of leadership these human resource issues are not being addressed. A need, therefore, exists that human resource management focuses on training and development that will lead to the public service having the best skilled workforce. The state must produce specialist technical skills that are necessary to fulfil its core functions and provide relevant career paths for technical specialists. According to the NDP, where skills are not available internally, departments rely on outside consultants, but this is a short-sighted approach that does not address where the next generation of senior public servants will come from. The focus should not just be on the skills that employees have presently, but also on those they could develop whilst working for the department or municipality, and recruitment and promotion processes need to place emphasis on skills and competence based on merit.

To this end, the Public Administration Management Act 2014 proposes the establishment of the National School of Government. The school must, through education and training, promote a progressive realisation of the values and principles governing public administration and enhance the quality, extent and impact of the development of human resource capacity in institutions. To ensure that candidates qualify for the positions they are appointed to, the Act mandates that the Minister for Public Service and Administration may, after approval by the cabinet, direct that the successful completion of specified education, training, examinations or tests is:

- a prerequisite for specified appointments

- compulsory in order to meet the development needs of any category of employees (section 13 [1])

Over and above the National School of Government, the NDP suggests the following initiatives:

- a formalised graduate recruitment scheme for the public service

- a career path for local government

- making adequate experience a prerequisite for senior posts

- a long-term perspective on training and development

\section{Lack of professionalisation of public service and local government}

In South Africa the focus should be on building a skilled and professional public service from the top to the bottom. The public service should attract and retain highly skilled people, cultivate a sense of professional purpose and a commitment to working towards development goals. The pool of skilled people should be increased by ensuring that the public service and local government become careers of choice for graduates who wish to contribute to the development of the country. Jam (as quoted in the NDP 2011) states:

[I]f we are to develop and maintain a professional, people and service orientated public service we need to ensure that the public service becomes a calling of excellence and a career which should be sought after, not for its financial gains and security, but because it is the haven for passionate patriots who want to serve ALL South Africans. (p. 371)

Public servants must be knowledgeable about the sections of society within which they work, and they must be connected to the communities they serve.

\section{Intergovernmental relations}

There are three spheres of government in the Republic of South Africa: national, provincial and local, which are interrelated (South Africa being a unitary state, with powers devolved to provincial and local spheres). There is, however, confusion about how responsibilities are divided, shared and monitored across the three spheres. Functionaries sometimes find themselves at a loss because at times there is no clarity in roles and functions. It is unavoidable that there will be disagreements about how roles and responsibilities are divided or shared but there should be some interventions to mediate. In this regard, recently the launch of the new integrated service delivery model 'Khawuleza' by President Cyril Ramaphosa is welcomed as a step in the right direction towards ironing out uncertainty in roles by the various spheres (Ramaphosa Foundation 2017). Also, the question of variation in capacity needs to be looked into, more so in municipalities where some have more capacity than others. A system needs to be developed whereby municipalities would share skills and capacity to the extent that more responsibilities would be devolved to those that have the skills and capacity.

Consideration should also be given to have a written document that lays out every single step of the intergovernmental system. Similar to a manual - this is because the Constitution only sets out the distribution of powers and functions between the three spheres.

Currently, according to Fitzgerald (2016), the strength and the role of the PSC seem to be weakened if the current challenges that the public sector is facing are anything to go by. The commission seems to be heading towards being a toothless dog. The current number of cases involves public sector corruption and cases that are never resolved within the 30 day turnaround time.

The PSS is established in terms of the Constitution 1996 to, inter alia, give directions aimed at ensuring that personnel procedures relating to recruitment, transfers, promotions and dismissals comply with the basic values and principles of the Constitution. It exists to advise and oversee how public institutions manage their human resources, without being involved in the selection process. However, it may be prudent to consider strengthening the role of the PSC to make it a champion of a meritocratic public service by promoting and monitoring key norms and standards in recruitment, especially for the most senior posts. This will ensure that recruitment into the public service is based on merit. It may, 
for example, be prudent that the PSC is involved in selection panels for senior management services (SMS) positions. This could ensure a transparent selection process that could reinforce confidence in the way that senior posts are filled in the public service.

\section{Poor organisational design}

In terms of the Public Service Act 1994, a number of human resource functions relating to organisational structure are in the hands of political heads of departments, who, at their discretion, may delegate these to administration heads. It happens at times that political heads choose not to delegate these powers and functions, some of which, if not all, have financial implications. Tensions arise when, in accordance with legislation, administrative heads have to account or answer for financial issues over which they have no control. This human resource issue is a recipe for conflict in any public institution and needs to be managed properly. Matters such as appointments, transfers, rights and privileges of employees have financial implications and should really be the responsibility of the administration head who, in terms of the Public Finance Management Act (1999), is officially responsible for financial issues.

\section{Career and talent management}

On the international front, the Kenyan PSC's Guide for Career Management in the Civil Service issued in April 2018 defines career management as the provision of opportunities for employees to develop their abilities and careers in order to ensure that the organisation has the flow of talent it needs and to satisfy its own aspirations. Whilst talent management is an organisation's commitment to recruit, hire, retain and develop the most talented and superior employees available in the job market, an individual employee is responsible to plan his or her career whilst the employer's role is to provide opportunities for career growth. To achieve this an organisation has to have an effective performance management and skills development programme that is geared towards the achievement of set objectives and its sustainability. The public service in South Africa offers job security, a variety of careers and opportunities for development. However, there are other factors that negate against the public service becoming an employer of choice, for instance, leadership instability coupled with the inability to recruit and sustain scarce skills in the public service. This has been more prevalent in the provincial administrations, particularly in rural and poor provinces. Added to this is the cadre deployment policy as practised by the governing party as is evident in the revelations of South African Revenue Services Commission of Inquiry headed by the retired judge Robert Nugent. The preference of local people for senior positions against merit during recruitment of personnel has a demoralising effect on the aspirant workforce.

In any organisation the litmus test for career management will be measured according to its ability to place the correct person in the correct position at the right time and who is capable to perform his or her allocated functions and responsibilities.

\section{The wellness of employee}

A critical human resource element that is almost always ignored or neglected by public institutions is the wellness of employees. When employees arrive at the office they bring with them their personal family problems, which have a bearing on their performance. If not managed properly, such problems may negatively affect the realisation of goals by an institution because a 'sick' employee will be unproductive. Managers need to consider the potential benefits of a system that is focused on pro-actively promoting and maintaining the mental and physical well-being of employees. The introduction of functional programmes, for example, Employee Assistance Programme (EAP), to address this issue may be necessary.

\section{Strengthen accountability and responsibility of public servants}

Accountability is answerability for one's actions. The actions of public servants must be above reproach, carried out in the open and not covered by a veil of secrecy, which may give rise to suspicion as against the Batho Pele Principles (1997)/ Labour Relations Act (66 of 1995). Public servants should be made legally answerable for their actions (NDP 2011:402); procurement details, for example, should be made available to citizens.

\section{The state capture by individuals and companies}

The Public Protector in the State of Capture Report revealed that employees, both political and administrative, in the South African public service, carry out their functions under the influence of individuals and companies who are outside the public service. This is referred to as state capture. Such conduct on the part of state employees is unethical and as a component of human resource management, employees who are found to be involved in it should be subjected to disciplinary action.

At the heart of the strategic priorities of any administration is the strengthening of public service and the developmental state to more effectively serve the needs of the people and act as a driving force for socio-economic transformation. The key priority in this regard is the strengthening of partnerships for development and ensuring more efficient and caring service delivery. Over the term, the government prioritises service delivery renewal, cooperative governance, shared services and organogram, reorganisation of the state, provision of access to broadband networks and building an active local government.

Government's biggest efforts are to build a democratic developmental state, which is not without its fair share of challenges, and many of our well-intentioned strategies have 
been hamstrung by inertia and the absence of agility in our poorly trained civil servants. In strengthening the developmental state and good governance, the Government's Medium Term Strategic Framework (GMTSF) objectives need strong monitoring mechanism through the Programme of Action that focuses on improving local government performance, provincial financial performance, planning, monitoring and evaluation, and public sector transformation.

So far since the dawn of democracy in 1994, South Africa has made significant progress in building the structures of a democratic state. The fragmented governance structures of apartheid have been rationalised into a system designed to serve developmental objectives. The composition of the public service and local government has been transformed to meet the needs of the entire population equally. Significant progress has been made in the provision of basic services, such as water, housing and electricity. The foundations for a state that is capable to provide for the welfare of its citizens have been laid, but there are concerns about the inability of these structures to function efficiently and effectively, which constrain the state's ability to pursue key developmental purposes. Human resources are an indispensable means to the provision of goods and services efficiently, effectively and economically. It is thus important that specific steps are carried out to obtain, develop and utilise personnel.

\section{Implications and recommendations}

- The state must foster strong collaborations with the institutions of higher learning for attracting young 'talent's with scarce skills before being snatched by the private sector and other provinces. Through these collaborations, the state must be able to influence the curriculum taught at the institutions of higher learning and advise on the courses that are on demand for the capable developmental state.

- There is also a need for the state to strengthen and market its recruitment and retention strategies to attract and keep particularly young, vibrant and highly qualified professionals in the public sector. Make the public sector an employee of choice. Avoid brain drain and migration to other provinces.

- Having the right people for the right functions helps the state to ensure that the exercise is undertaken by all government departments and outcomes are implemented. This has a potential of causing some tensions; however, it is necessary to ensure that human resources are utilised to the maximum.

- Some government departments are still functioning with obsolete organisational structures, despite the dynamics, paradigm shift and complexities in government.

- Have a clear succession plan and get to the next level ready for the takeover when the time comes. Encourage the uptake of the government's offer of voluntary early retirement.

\section{Conclusion}

In conclusion, if South Africa needs to be successful in transforming society into a state of capability and development, capable of formulating and implementing policies that serve the national interest, it needs to be developmental in that it should focus on those policies that would overcome the root causes of poverty and inequality and build the capacity of the state to fulfil that role. In Parnell's words, for South Africa to call itself Developmental Government must refer to being able to play a transformative role in tackling poverty and inequality. This requires well-run and effectively coordinated state institutions with competent public servants who are committed to the public good and able to deliver consistently high-quality services whilst prioritising the development goals of the nation. Finally, the NDP makes it clear that cooperation and communication are necessary for South Africa to transcend social and economic divides. This extends in all three integrated and concise policy domains, and in cooperation with the civil society and business sector. Individual initiatives, a tendency to move from one quick fix or tendency to another and frequent changes have generated uncertainty in organisational structures and strained power. It is needless to say that the nation needs to make local government stronger. Build an enabling structure for local government (e.g. it may include organisational guidance for routine tasks) with strong national and provincial government support and oversight. It includes clarification of position, and prioritisation of participation by people. Create delegation, transparency and oversight. Make it easier for people to hold accountable for public servants and politicians, particularly for the quality of service delivery. There is a need for streamlined processes which maintain checks and balances and explain accountability whilst making decisions easier. Civil society can also play a role in monitoring government data, whilst government encourages this by ensuring that data are available in appropriate formats (Open Data).

\section{Acknowledgements}

The authors would like to extend their appreciation and profound gratitude to all those who directly or indirectly participated in and contributed to this study.

\section{Competing interests}

The authors declare that they have no financial or personal relationships that may have inappropriately influenced them in writing this article.

\section{Authors' contributions}

T.R.M. was responsible for data analysis and refined the article for submission. X.G.N. was responsible for literature review and worked on the draft version.

\section{Ethical consideration}

Ethical clearance was not required for this study. The research took into consideration key ethical issues such as the freedom of respondents to participate in the study or not. The 
objectives of the research were clearly explained to them. The respondents were not coerced to join the study. To keep respondents' privacy, identification was not necessary. The interviews were conducted in the languages the respondents understood the best.

\section{Funding information}

This research received no specific grant from any funding agency in the public, commercial or not-for-profit sectors.

\section{Data availability statement}

Data sharing is not applicable to this article as no new data were created or analysed in this study.

\section{Disclaimer}

The views and opinions expressed in this article are those of the authors and do not necessarily reflect the official policy or position of any affiliated agency of the authors.

\section{References}

Adelzadeh, A. \& Padayachee, V., 1994, 'The RDP White Paper: Reconstruction of a development vision', Transformation 25(5), 1-18.

Cyril Ramaphosa Foundation, 2017, Thuma Mina Campaign, CRF House, Sandton.

Dlodlo, A., 2018, At the launch of the 2018 Public Service month, Velmore Conference Centre, Tshwane.
Fitzgerald, P., 2016, Building a capable state, Or tambo debate series, Wits School of Governance, University of the Witwatersrand, Johannesburg.

Government Gazette, 1995, Labour Relations Act (66 of 1995), Government Printers, Pretoria, South Africa.

Grant, C. \& Azadeh, O., 2014, 'Understanding, selecting and integrating a theoretical framework in dissertation research: Creating the blueprint for your "House", Administrative Issues Journal: Connecting Education, Practice, and Research 4(2), 1-15. https://doi.org/10.5929/2014.4.2.9

Heaton, J., 2004, Reworking qualitative data, Sage, Thousand Oaks, California.

Johnson, C., 1999, 'The developmental state: Odyssey of a concept', in M. WooCumings (ed.),' The developmental state, Cornell University Press, New York, NY.

Kanyane, M.H., Mle, T. \& Maclean, S., 2015, Policy decisions and their implications on service delivery in South Africa, in C.O.K. Allen-Ile, M.H. Kanyane \& I.U. Ile (eds) Governance and resource management in southern Africa: Challenges and opportunities for advancement, Reach Publishers, Durban, pp. 2-15.

Leedy, P.D., 1989, Practical research: Planning and design, Collier Macmillan publishing company, London.

Meiring, M.H. \& Parsons, C.R., 1994, Fundamental public administration: A guide for a changing South Africa, University of Port Elizabeth Press, Port Elizabeth.

National Development Plan Vision for 2030, 2011, National planning commission, Republic of South Africa, Government Printers, Pretoria.

National Planning Commission, 2012, National Development Plan 2030: Our futuremake it work, Government Printers, South Africa.

Palmer, I., Moodley, N. \& Parnell, S., 2017, Building a capable state: Service delivery in post-apartheid South Africa, Zed Books Ltd., London.

Parliament of the Republic of South Africa, 1994, White Paper on reconstruction and development, Ministry in the Office of the President, Creda Press, Cape Town.

Public Service Commission, 2007, PSC Annual Report to Citizens for the 2006/2007 Financial Period, Government Printers, South Africa.

Qobo, M., 2020, What it will take to build a capable state in South Africa, The Conversation, Braamfontein.

Republic of South Africa, 1996, The Constitution of the Republic of South Africa Act, Government Printers, Pretoria.

South African Government, 1997, Transforming Public Service Delivery (Batho Pele White Paper), Department of Public Service and Administration, Government Printers, South Africa.

The Public Administration Management Act 11 of 2014, 2014, Government Gazette No. 1054, The Presidency, Cape Town. 